\title{
Correction: prevalence and socioeconomic correlates of overweight and obesity among Pakistani primary school children
}

\author{
Muhammad Umair Mushtaq ${ }^{1,2^{*}}$, Sibgha Gull ${ }^{3}$, Hussain Muhammad Abdullah', Ubeera Shahid', \\ Mushtaq Ahmad Shad ${ }^{2}$ and Javed Akram ${ }^{1}$
}

\section{Text}

Since the publication of our article [1], we have noticed some errors in the final published version, for which the corresponding author accepts full responsibility. Page references are to the final PDF version.

Page 3: Results, second paragraph Lines 1-2: "BMI... 20.7 (5.02) $\mathrm{kg} / \mathrm{m}^{2} \ldots$.. should read "BMI. . $16.0(3.0) \mathrm{kg} / \mathrm{m}^{2} \ldots$.."

Lines 6-8: "According to the IOTF cut-offs, overweight and obesity prevalence was $33 \%$ (95 \% CI 31.1-35.3) and $24 \%$ (95 \% CI 22.4-26.2) respectively" should read "According to the IOTF cut-offs, overweight and obesity prevalence was $8.3 \%$ (95\% CI 7.1-9.6) and $4.7 \%$ (95\% CI 3.8-5.7) respectively"

\section{Page 4: Table 1}

The values for mean and standard deviation (SD) for BMI $\left(\mathrm{kg} / \mathrm{m}^{2}\right)$ are revised.

\section{Page 4: Table 2}

The values for mean BMI (SD) and overweight and obesity prevalence according to the IOTF cut-offs are revised.

* Correspondence: mushtaqmu@gmail.com

${ }^{1}$ Ubeera Memorial Research Society, Allama lqbal Medical College, Lahore,

Punjab 54000, Pakistan

${ }^{2}$ District Health Office Nankana Sahib, Punjab Department of Health, Nankana Sahib, Punjab 39100, Pakistan

Full list of author information is available at the end of the article

\section{Page 5: Figure 1}

The values for grade- and gender- specific mean BMI are revised.

\section{Page 6: Second paragraph}

Lines 1-8: "Prevalence of overweight by the IOTF cutoffs was twice the prevalence by the WHO 2007 reference (33 \% versus $17 \%$ ) and prevalence of obesity by the IOTF cutoffs was three times higher than that calculated by the WHO 2007 reference (24\% versus $7.5 \%$ ). Using IOTF cut-offs for overweight and obesity in Pakistani schoolaged children would result in higher estimates than the WHO 2007 reference." should read "Prevalence of overweight by the IOTF cut-offs was half the prevalence by the WHO 2007 reference ( $8 \%$ versus $17 \%$ ) and prevalence of obesity by the IOTF cutoffs was two-third of that calculated by the WHO 2007 reference (5\% versus $7.5 \%$ ). Using IOTF cut-offs for overweight and obesity in Pakistani schoolaged children would result in lower estimates than the WHO 2007 reference. A relatively lower overweight and obesity prevalence with use of the IOTF cut-offs as compared to the WHO reference had been reported elsewhere [2,3]."

In present study, the estimates for overweight included obese children.

\section{Competing interests}

The authors declare that they have no competing interests.

\section{Authors' contributions}

All authors contributed significantly in all phases of the study in accordance with uniform requirements established by the International Committee of Medical Journal Editors. All authors read and approved the final manuscript.

\section{Author details}

${ }^{1}$ Ubeera Memorial Research Society, Allama lqbal Medical College, Lahore, Punjab 54000, Pakistan. ²District Health Office Nankana Sahib, Punjab Department of Health, Nankana Sahib, Punjab 39100, Pakistan. ${ }^{3}$ King Edward Medical University, Lahore, Punjab 54000, Pakistan. 
Table 1 Mean and standard deviation (SD) for height, weight and BMI of primary school children in Lahore, Pakistan ( $n=1860)$

\begin{tabular}{|c|c|c|c|c|}
\hline Characteristics & $\mathbf{n}$ & Height $(\mathrm{cm})$ & Weight (kg) & BMI $\left(\mathrm{kg} / \mathrm{m}^{2}\right)$ \\
\hline \multicolumn{5}{|l|}{ Boys $(n=977)$} \\
\hline 5 years (61-71 months) & 84 & $113.7(7.3)$ & $19.9(4.6)$ & $15.2(2.1)$ \\
\hline 6 years (72-83 months) & 161 & $118.3(5.9)$ & $21.6(5.0)$ & $15.3(2.8)$ \\
\hline 7 years (84-95 months) & 160 & $122.9(8.0)$ & $23.5(5.1)$ & $15.5(2.4)$ \\
\hline 8 years (96-107 months) & 158 & $128.7(7.6)$ & $26.9(5.9)$ & $16.1(2.5)$ \\
\hline 9 years (108-119 months) & 161 & $134.2(8.1)$ & $29.7(7.6)$ & $16.4(3.1)$ \\
\hline 10 years (120-131 months) & 147 & $138.4(8.0)$ & $33.3(9.5)$ & $17.2(3.5)$ \\
\hline 11 years (132-143 months) & 69 & $138.6(7.7)$ & $31.8(6.8)$ & $16.5(2.7)$ \\
\hline 12 years (144-155 months) & 37 & $140.0(8.3)$ & $31.8(7.3)$ & $16.1(2.3)$ \\
\hline \multicolumn{5}{|l|}{ Girls $(n=883)$} \\
\hline 5 years (61-71 months) & 72 & $115.4(7.3)$ & $19.3(3.2)$ & $14.4(1.5)$ \\
\hline 6 years (72-83 months) & 143 & $119.1(7.6)$ & $21.0(4.9)$ & $14.7(2.4)$ \\
\hline 7 years (84-95 months) & 157 & $124.0(6.3)$ & $24.0(5.5)$ & $15.5(2.7)$ \\
\hline 8 years (96-107 months) & 159 & $128.1(7.1)$ & $26.4(6.8)$ & $15.9(2.9)$ \\
\hline 9 years (108-119 months) & 151 & $133.3(7.8)$ & $30.4(8.2)$ & $17.0(3.5)$ \\
\hline 10 years (120-131 months) & 120 & $138.4(9.3)$ & $33.3(10.1)$ & $17.2(3.8)$ \\
\hline 11 years (132-143 months) & 62 & $143.3(9.6)$ & $36.5(11.0)$ & $17.5(3.7)$ \\
\hline 12 years (144-155 months) & 19 & $146.0(9.4)$ & $36.4(9.9)$ & $16.9(3.3)$ \\
\hline
\end{tabular}

Table 2 Prevalence of overweight and obesity among primary school children in Lahore, Pakistan $(\mathbf{n}=1860)$

\begin{tabular}{|c|c|c|c|c|c|c|}
\hline & & & WHO 2007 & & IOTF & IOTF \\
\hline Characteristics & $\mathbf{n}$ & Mean BMI (SD) & $\%(95 \% \mathrm{Cl})$ & Mean BMI-for-age z-score (SD) & $\%(95 \% \mathrm{Cl})$ & \\
\hline Severely obese & 36 & $25.7(2.9)$ & $1.9(1.3-2.6)^{a}$ & $3.7(0.7)$ & & \\
\hline Obese & 140 & $23.4(2.8)$ & $7.5(6.3-8.7)^{b}$ & $2.8(0.7)$ & $4.7(3.8-5.7)^{d}$ & \\
\hline Overweight & 316 & $21.2(2.9)$ & $17.0(15.4-18.8)^{c}$ & $2.0(0.8)$ & $8.3(7.1-9.6)^{e}$ & \\
\hline Total sample & 1860 & $16.0(3.0)$ & & $-0.3(1.5)$ & & \\
\hline
\end{tabular}

${ }^{a}>+3 S D,{ }^{b}>+2 S D,{ }^{c}>+1 S D$ of World Health Organization (WHO) 2007 BMl-for-age reference.

d, eInternational Obesity Task Force (IOTF) cut-offs for obesity and overweight respectively.

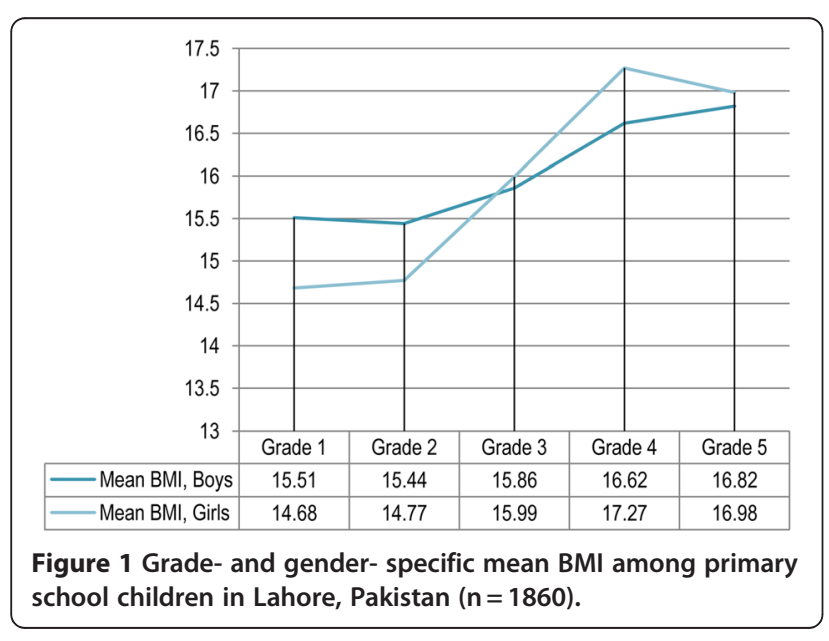

Received: 4 July 2012 Accepted: 4 July 2012 Published: 20 July 2012

\section{References}

1. Mushtaq MU, Gull S, Abdullah HM, Shahid U, Shad MA, Akram J: Prevalence and socioeconomic correlates of overweight and obesity among Pakistani primary school children. BMC Publ Health 2011, 11(1):724

2. Kain J, Uauy R, Vio F, Albala C: Trends in overweight and obesity prevalence in Chilean children: comparison of three definitions. Eur J Clin Nutr 2002, 56(3):200-204.

3. Krebs NF, Himes JH, Jacobson D, Nicklas TA, Guilday P, Styne D: Assessment of Child and Adolescent Overweight and Obesity. Pediatrics 2007, 120: S193-S228.

doi:10.1186/1471-2458-12-532

Cite this article as: Umair Mushtaq et al:: Correction: prevalence and socioeconomic correlates of overweight and obesity among Pakistani primary school children. BMC Public Health 2012 12:532. 